\title{
Incidence of NIDDM and the effects of gender, obesity and hyperinsulinaemia in Taiwan
}

\author{
S.-L. Wang ${ }^{1}$, W.-H. Pan ${ }^{1}$, C.-M. Hwu ${ }^{2,4}$, L.-T. Ho ${ }^{2-4}$, C.-H. Lo ${ }^{5}$, S.-L. Lin ${ }^{6}$, Y.-S. Jong \\ ${ }^{1}$ Institute of Biomedical Sciences, Academia Sinica, Taipei, Taiwan, R. O. C. \\ ${ }^{2}$ Section of Endocrinology and Metabolism, Department of Medicine, Veterans General Hospital, Taipei, Taiwan, R. O. C. \\ ${ }^{3}$ Department of Medical Research and Education, Veterans General Hospital, Taipei, Taiwan, R. O. C. \\ ${ }^{4}$ Department of Medicine, Medical College, National Yang-Ming University, Taipei, Taiwan, R. O. C. \\ ${ }^{5}$ Provincial Chu-Dung Hospital, Hsin-Chu, Taiwan, R. O. C. \\ ${ }^{6}$ Provincial Pu-Tzu Hospital, Chia-Yi, Taiwan, R. O. C.
}

Summary Our aim is to determine non-insulin-dependent diabetes mellitus (NIDDM) incidence in Taiwan and examine its relation to obesity and hyperinsulinaemia in Chinese men and women. A total of 995 men and 1195 women aged 35-74 years free from diabetes in two townships in Taiwan were followed up with a second examination. At baseline general and metabolic data were recorded, and detailed anthropometric parameters and plasma glucose and insulin were assessed. World Health Organisation (WHO) criteria of fasting glucose $7.8 \mathrm{mmol} / \mathrm{l}$ or greater was utilized for defining diabetes. The age-standardized incidence rate based on the United States population in 1970 was $9.3 / 1000$ (CI 5.8-12.8) in men and 9.3/1000 (CI 6.2-12.4) in women and the based on the WHO population in 1976 was 8.9/1000 (CI .512.3) in men and 8.9/1000 (CI 5.9-11.9) in women for the Chinese who had a mean BMI slightly greater than $24\left(\mathrm{~kg} / \mathrm{m}^{2}\right)$. The predictability of the plasma glucose level was greater than that of the insulin level and the obesity indices. NIDDM incidence increased approximately threefold with each $0.67 \mathrm{mmol} / 1$ increase in plasma glucose level in men and women. The present study demonstrated the essential relationship of not only BMI but also central obesity indices (such as subscapular and waist circumference) to the incidence of NIDDM among men and women and a stronger relationship between NIDDM incidence and obesity in women than in men. The predictive effects of obesity indices and fasting plasma insulin values on NIDDM risk were independent of each other in men. Obesity and hyperinsulinaemia each without the presence of the other can lead to an increased risk of NIDDM. In women the NIDDM incidence increased more than additively in those with both obesity and hyperinsulinaemia compared to those with single obesity or hyperinsulinaemia. A slightly higher incidence of NIDDM in Taiwan than in western countries was found. The importance of obesity is indicated for predicting NIDDM in the community. Hyperinsulinaemia was found to play a significant role in predicting NIDDM incidence independent of obesity in men and synergistically with obesity in women. [Diabetologia (1997) 40: 1431-1438]

Keywords Non-insulin-dependent diabetes mellitus, incidence, risk factors, anthropometry, obesity, insulin-blood, Taiwan-epidemiology.
Received: 20 January 1997 and in final revised form: 11 June 1997

Corresponding author: W.-H. Pan, Ph.D., Institute of Biomedical Sciences, Academia Sinica, No. 128, Sec. 2, Academia Sinica Rd. Taipei 11529, Taiwan, R. O. C.

Abbreviations: BMI, Body mass index; WHR, waist hip ratio; Waist C, waist circumference; Hip C, hip circumference; Triceps, triceps skin-fold thickness; subscap, sub-scapular skinfold thickness; Arm C, upper arm circumference; Glucose, fasting plasma glucose; Insulin, fasting plasma insulin; CI, confidence interval; RR, relative risk; OGTT, oral glucose tolerance test; CVDFACTS, CardioVascular Disease risk FACtor Two-township Study
Previous studies of diabetes mellitus in Taiwan have shown that it is an important disease in terms of prevalence [1, 3] and mortality [2]. In the 1950 s diabetes was not even within the top 10 causes of death. Today it has become the fifth leading cause of death which ranks along with cancer, stroke, accident and heart disease. In women aged 55-69 years, diabetes also ranks as the third cause of mortality [2]. Although prevalence of diabetes has been found to be high [1, $3]$, there is little data on the incidence of the disease in the general population in Taiwan. The present 
study presents incidence data of non-insulin-dependent diabetes mellitus (NIDDM) and its relation to gender, various obesity indices and insulin level in a community-based population.

Regarding the risk factors for NIDDM, many studies have shown an increased prevalence of NID$\mathrm{DM}$ in individuals with abdominal fat accumulation, but there are still relatively few prospective studies. Earlier cohort studies have shown an association between obesity and NIDDM incidence for men [4-6], and for the general population in the Netherlands [7]. Furthermore, in the 8-year follow-up study of Mexican-Americans of both sexes [8], increased waist circumference was found to be more strongly associated with diabetes in women than in men. However, an elevated insulin concentration which is observed in both obese and NIDDM patients was not considered in these studies. An association between insulin and NIDDM incidence has been documented for Pima Indians [9], Micronesians from the island of $\mathrm{Na}-$ uru [10], Mexican-Americans [23, 24] and a relationship has also been reported between C-peptide and NIDDM for Japanese-Americans [5]. The current study takes both obesity and insulin into account separately for males and females. Moreover, we examined the interaction between obesity and hyperinsulinaemia on NIDDM incidence.

\section{Subjects and methods}

Study population. The CardioVascular Disease risk FACtor Two-township Study (CVDFACTS) has been in progress since November 1990. A description of the cohort has been detailed previously [11]. One town (Chu-Dung) is located in the northwest and the other $(\mathrm{Pu}-\mathrm{Tzu})$ in the south-west of Taiwan. Five villages in each of the two townships were randomly selected from those with more than 1000 people or which had a population density greater than 200 per square kilometer. All the residents in the total of 10 villages were invited to participate in the study with an invitation describing the study and its purpose. Second and third notices were sent to those who did not respond. The baseline cohort was followed up to August 1996.

The initial response rate of the invited families was $67 \%$. The baseline measurements were carried out between November 1990 and September 1993. A total of 3401 subjects aged 35-74 years with all investigated factors measured and free of NIDDM by World Health Organisation criteria [12] at baseline were followed up to 5 years in a second examination between December 1993 and October 1996. The average followup period was 3.3 years. The incidence of NIDDM was based on two single follow-up glucose measurements and information on diabetic medication in the first and second examinations. From our observations, new cases of diabetes under the age of 35 years were rare. Including subjects aged 25-34 years will result in a reduction of statistical power because of the small numbers. Therefore, the lower age limit was set at 35 years. The upper age limit was set at 74 years since the observation of the disease in people above age of 75 years would be affected by mortality. For those present at the initial baseline examination but not at the follow-up intervals, three phone calls and two home visits were made. Questionnaires, blood sampling for glucose and insulin testing, and anthropometric measurements were completed at home visits if the subjects were unable to come to the clinical centres for full examinations.

Data collection. Anthropometric measurements have been previously described in detail [13]. All measurements were performed by the same team of two trained technicians. Height and weight were measured in light clothing without shoes. Body mass index (BMI) was calculated as weight $(\mathrm{kg})$ divided by height (m) square. Circumferences of mid-upper-arm (Arm C), waist (Waist C) and hip (Hip C) were measured using cloth anthropometric tape. Waist-hip ratio (WHR) was calculated as Waist $\mathrm{C}$ divided by Hip C. Triceps (Triceps) and subscapular (Subscap) skinfold thickness was measured twice by Harpendon skinfold calipers and the average data were calculated for statistical analyses. Venous blood specimens were obtained after a $10 \mathrm{~h}$ fast without smoking before the examinations. The blood samples were centrifuged within $30 \mathrm{~min}$, and the plasma was collected and stored at $-70^{\circ} \mathrm{C}$ while waiting for the measurements of glucose and insulin concentrations. Plasma insulin concentration was measured by Coat-A-Count Insulin Radioimmunoassay (RIA) kit (Los Angeles, CA, USA). Its cross-reactivity with proinsulin at mid-curve was approximately $40 \%$.

Statistical analysis. NIDDM subjects were defined as those who corresponded to the WHO criteria of fasting plasma glucose level greater than or equal to $7.8 \mathrm{mmol} / \mathrm{l}$ or taking anti-diabetic therapy. Age-adjusted incidence (Table 3) was calculated by direct standardization using the age distribution of the WHO world population in 1976 and the United States population in 1970 [14]. Confidence Intervals (CI) of the incidence rates were calculated according to binomial distribution [15]. For the descriptive analyses and regression models, the Statistical Analysis System (SAS) software was utilized [16]. The baseline characteristics were compared between those successfully followed and those lost to follow-up by ANCOVA (analysis of covariance) adjusting for the effect of age (Table 1). The same approach was used to compare between diabetic and non-diabetic groups (Table 2). Age-adjusted logistic regression analyses were performed to compare the effects of fasting plasma glucose (glucose), insulin (insulin) values and several obesity indices as linear variables in predicting NIDDM incidence (Table 4). Insulin was further adjusted in the logistic regression to examine the independent effects of obesity indices (Table 5). In the same regression models, the results for insulin level were also shown in Table 5 to compare partial $p$-values of insulin and obesity indices. Relative Risk (RR) for each risk factor was standardized to correspond to the risk given one standard deviation (SD) change and the SD of each independent variable was shown.

In order to assess the interaction of obesity and hyperinsulinaemia, NIDDM incidence was calculated in four groups: those without obesity or hyperinsulinaemia, those with single obesity or hyperinsulinaemia, and those with both. In this analysis, subjects with obesity were defined as men with waist girth $84.2 \mathrm{~cm}$ or more (76.4 for women), BMI $24.0 \mathrm{~kg} / \mathrm{m}^{2}$ or more (23.9 for women), subscapular skinfold thickness $1.52 \mathrm{~m}$ or more (1.86 for women) and arm circumference $30.0 \mathrm{~cm}$ or more (28.6 for women). The $50^{\text {th }}$ percentile values of the obesity indices were selected as the above cutoff points to ensure proper interpretation of data and sufficient number of subjects in the obese category. Subjects with hyperinsulinaemia were those with fasting plasma insulin concentration $66 \mathrm{pmol} / \mathrm{l}$ for both sexes. 
Table 1. Age-adjusted baseline characteristics in those successfully followed-up and in those lost to follow-up

\begin{tabular}{|c|c|c|c|c|c|c|}
\hline & \multicolumn{3}{|l|}{ Men } & \multicolumn{3}{|l|}{ Women } \\
\hline & Followed (CI) & Lost (CI) & $p$-value & Followed (CI) & Lost (CI) & $p$-value \\
\hline$n$ & 995 & 542 & & 1195 & 669 & \\
\hline Glucose $(\mathrm{mmol} / \mathrm{l})$ & $5.81(5.73-5.90)$ & $5.97(5.72-6.21)$ & 0.21 & $5.75(5.67-5.84)$ & $6.00(5.80-6.16)$ & 0.029 \\
\hline Insulin $(\mathrm{pmol} / \mathrm{l})$ & $53.0(48.8-57.3)$ & $72.6(37.6-107.6)$ & 0.28 & $72.8(54.4-109.0)$ & $94.0(56.2-131.6)$ & 0.125 \\
\hline \multicolumn{7}{|l|}{ Obesity indices } \\
\hline Hip C $(\mathrm{cm})$ & $95.3(95.0-95.7)$ & $99.5(94.1-95.3)$ & 0.10 & $95.8(95.5-96.2)$ & $96.8(96.0-97.3)$ & 0.020 \\
\hline WHR & $0.89(0.89-0.90)$ & $0.90(0.89-0.91)$ & 0.045 & $0.81(0.81-0.82)$ & $0.84(0.83-0.84)$ & 0.0001 \\
\hline BMI $\left(\mathrm{kg} / \mathrm{m}^{2}\right)$ & $24.2(24.0-24.3)$ & $23.9(23.6-24.2)$ & 0.27 & $24.4(24.3-24.6)$ & $25.1(24.7-25.3)$ & 0.002 \\
\hline Triceps (mm) & $12.5(12.1-12.9)$ & $11.6(11.0-12.2)$ & 0.028 & $21.4(20.7-22.0)$ & $21.4(20.2-22.8)$ & 0.99 \\
\hline $\operatorname{Arm~C~}(\mathrm{cm})$ & $29.8(29.6-30.0)$ & $29.2(28.8-29.5)$ & 0.002 & $28.9(28.7-29.0)$ & $29.2(28.8-29.4)$ & 0.06 \\
\hline
\end{tabular}

Mean values for risk variables were age-adjusted and tested by analysis of covariance (ANCOVA)

Table 2. Age-adjusted baseline characteristics by non- and new-diabetic groups at follow-up

\begin{tabular}{|c|c|c|c|c|c|c|}
\hline & \multicolumn{3}{|l|}{ Men } & \multicolumn{3}{|l|}{ Women } \\
\hline & Non-diabetic & Diabetic & $p$-value & Non-diabetic & Diabetic & $p$-value \\
\hline$N$ & 967 & 28 & & 1163 & 32 & \\
\hline Glucose $(\mathrm{mmol} / \mathrm{l})$ & $5.47(5.42-5.51)$ & $6.41(5.96-6.87)$ & 0.0006 & $5.37(5.33-5.40)$ & $6.20(5.92-6.47)$ & 0.0000 \\
\hline Insulin (pmol/l) & $46.3(43.4-49.3)$ & $136.8(12.8-219.1)$ & 0.0561 & $52.9(49.8-56.0)$ & $82.4(59.6-105.3)$ & 0.0015 \\
\hline \multicolumn{7}{|l|}{ Obesity indices } \\
\hline Hip C $(\mathrm{cm})$ & $95.1(94.7-95.5)$ & $99.4(96.6-102.2)$ & 0.0003 & $95.6(95.4-96.0)$ & $101.6(98.9-104.3)$ & 0.0000 \\
\hline WHR & $0.886(0.88-0.89)$ & $0.92(0.90-0.95)$ & 0.0023 & $0.804(0.80-0.81)$ & $0.85(0.83-0.87)$ & 0.0000 \\
\hline BMI $\left(\mathrm{kg} / \mathrm{m}^{2}\right)$ & $23.9(23.8-24.1)$ & $26.2(25.0-27.5)$ & 0.0001 & $24.2(24.0-24.4)$ & $28.6(27.2-29.9)$ & 0.0000 \\
\hline Triceps (mm) & $12.0(11.7-12.3)$ & $13.7(12.3-15.2)$ & 0.0699 & $19.4(19.1-19.8)$ & $22.0(19.7-24.3)$ & 0.0195 \\
\hline $\operatorname{Arm} C(\mathrm{~cm})$ & 29.7 (29.5-29.9) & $31.6(30.6-32.6)$ & 0.0037 & $28.7(28.5-28.9)$ & $32.1(30.8-33.4)$ & 0.0000 \\
\hline
\end{tabular}

Subjects with diabetes at baseline have been excluded.

Mean values for risk variables were age-adjusted and tested by analysis of covariance (ANCOVA)

\section{Results}

A total of 252 subjects (6.9\% of the baseline cohort) with NIDDM at baseline were excluded based on fasting glucose $7.8 \mathrm{mmol} / \mathrm{l}$ or more or anti-diabetic therapy. A total of 995 men and 1195 women were successfully followed up, achieving a rate of $64 \%$. Table 1 shows the comparisons of all risk variables examined between those who were successfully followed-up and those who were not. Men lost to follow-up were 1.4 years younger and their age-adjusted Arm C and Triceps were slightly lower than those of the followed-up men. In women, those lost were generally more obese and had higher glucose levels than those followed-up.

Table 2 shows the baseline characteristics of subjects with and without diabetes at the time of followup. Those who developed NIDDM at the follow-up tended to be significantly older, having higher ageadjusted values of Waist C, Hip C, WHR, Subscap, BMI, and Arm C. A significant difference of triceps skinfold thickness was only observed in women. The difference between non-diabetic and diabetic groups in baseline obesity indices tended to be greater in women than in men. This phenomenon was most apparent in Subscap. Those who developed NIDDM also had significantly higher levels of fasting plasma glucose $(6.41 \mathrm{mmol} / 1$ vs 5.47 in men and 6.20 vs 5.37 in women) and insulin concentration (136.8 pmol/1 vs 46.3 in men, and 82.4 vs 52.9 in women) than those who remained non-diabetic.

A total of 60 subjects without diabetes at baseline subsequently developed the disease (Table 3). NIDDM incidence rates increased with increasing age from 4.8 per 1000 person-years for men (3.4 for women) aged 35-45 years to 18.5 per 1000 (14.9 for women) aged 65-74 years. Women had higher rates than men in the age range 45 to 64 years, whereas men aged 65-74 years experienced much higher rates. Overall, the age-standardized rate in men aged 3574 years was the same as that in women.

From Figure 1, NIDDM incidence increased considerably once the fasting plasma glucose level reached $5.79 \mathrm{mmol} / \mathrm{l}$ or more, with an eightfold increased risk compared to the second (no new NIDDM cases in the first) quartile in women and 
Table 3. Age and gender specific diabetes incidence per 1000

\begin{tabular}{|c|c|c|c|c|c|c|c|}
\hline & & \multicolumn{3}{|l|}{ Men } & \multicolumn{3}{|l|}{ Women } \\
\hline & & $n / N$ & $\begin{array}{l}\text { Person- } \\
\text { years }\end{array}$ & $\begin{array}{l}\text { Incidence Rate } \\
(95 \% \mathrm{CI})\end{array}$ & $n / N$ & $\begin{array}{l}\text { Person- } \\
\text { years }\end{array}$ & $\begin{array}{l}\text { Incidence Rate } \\
(95 \% \mathrm{CI})\end{array}$ \\
\hline
\end{tabular}

Subjects with diabetes at baseline have been excluded in this analysis

$\mathrm{n} / \mathrm{N}$, New diabetes cases/total number of people at risk
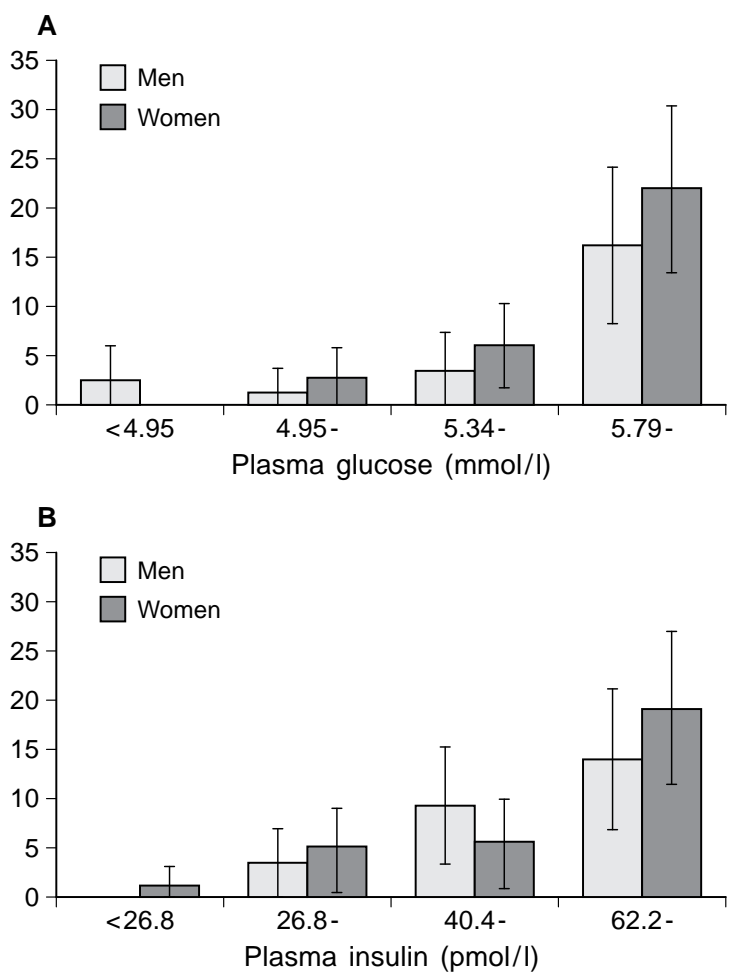

Fig. 1A, B. NIDDM incidence (per 1000 person years) by quartiles of plasma glucose (A) and insulin levels (B) with $95 \%$ confidence interval

11.4-fold in men. NIDDM incidence also increased with increasing insulin concentration, reaching 13.9 and 19.2 per 1000 at $62.2 \mathrm{pmol} / \mathrm{l}$ in men and women, respectively.

The results of logistic regression in Table 4 show that glucose and insulin concentrations were significantly associated with NIDDM incidence after adjustment for age in both men or women. NIDDM incidence increased around three times for each $0.67 \mathrm{mmol} / \mathrm{l}$ increase (one standard deviation) in the fasting plasma glucose level for men and women.
Age distributions of the United States population (1970), of the Europe population (1976) and of the WHO world population (1976) aged 35-74 years were utilized for age standardization

NIDDM incidence increased more than twice for men and 1.5 times for women in each increase of approximately $43 \mathrm{pmol} / \mathrm{l}$ in insulin level. The age-adjusted effect of glucose level was greater than plasma insulin as also shown in Table 5 when both factors were in the multiple logistic regression model.

In terms of the relationship between obesity and NIDDM incidence (Table 4), indices for measuring obesity at the trunk (particularly Waist C and Subscap) and for general obesity (BMI) predicted incidence better than indices for the extremes of the body such as Triceps and Arm C. A stronger relation between NIDDM incidence and obesity was observed in women than in men particularly for Waist C, BMI, Subscap and Arm C. It is worth noting that WHR was not as a good a predictor as Waist C.

Insulin was further adjusted in addition to age (Table 5) to examine the independent effect of obesity on NIDDM incidence. In addition we also showed an effect of insulin independent of age and obesity indices (or glucose). We found that the effect of fasting plasma insulin level was more significant than those of all obesity indices in men by comparing the $p$-values. In addition, the effects of insulin and obesity were independent of each other. But in women, the effect of obesity indices was greater and more significant than that of insulin level. The effect of obesity was independent of insulin, but not vice versa.

Figure 2 shows that men with obesity experienced a higher risk of NIDDM incidence regardless of the coincidence of increased insulin level $(p=0.0113)$. On the other hand, men with hyperinsulinaemia also had a higher risk of NIDDM in either the obese group or the non-obese group at a borderline significant level $(p=0.0585)$. However, in women a significant interaction between obesity and hyperinsulinaemia $(p=0.0106)$ was observed. The incidence increased more than additively with the occurrence of obesity and hyperinsulinaemia together compared to 
Table 4. Standardized relative risk of NIDDM incidence for examined variables by logistic regression analysis - adjusted for age

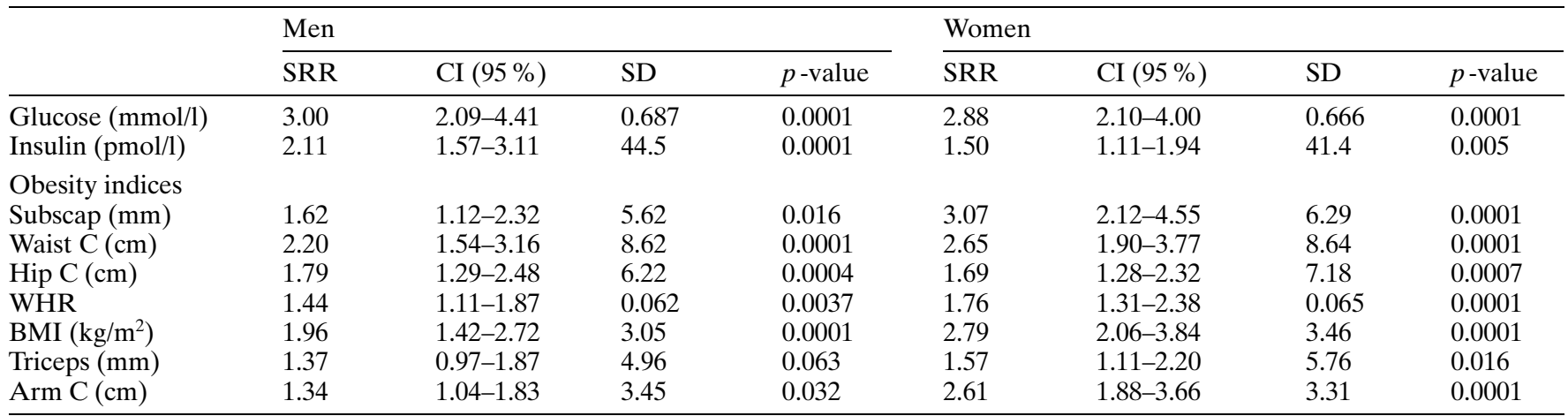

SRR, Standardized Relative Risk;

$\mathrm{SD}$, standard deviation of the independent variables

Table 5. Standardized relative risk of NIDDM incidence for examined variables by logistic regression analysis - adjusted for age and insulin

\begin{tabular}{|c|c|c|c|c|c|c|}
\hline \multirow[t]{2}{*}{ Factor } & \multicolumn{3}{|l|}{ Men } & \multicolumn{3}{|c|}{ Women } \\
\hline & SRR & CI (95\%) & $p$-value & SRR & CI (95\%) & $p$-value \\
\hline $\begin{array}{l}\text { Subscap }(\mathrm{mm}) \\
\text { Insulin }(\mathrm{pmol} / \mathrm{l})\end{array}$ & $\begin{array}{l}1.06 \\
1.91\end{array}$ & $\begin{array}{l}0.50-2.12 \\
1.39-2.83\end{array}$ & $\begin{array}{l}0.88 \\
0.0096\end{array}$ & $\begin{array}{l}2.37 \\
1.43\end{array}$ & $\begin{array}{l}1.49-3.88 \\
1.00-1.91\end{array}$ & $\begin{array}{l}0.0004 \\
0.029\end{array}$ \\
\hline $\begin{array}{l}\text { Waist C }(\mathrm{cm}) \\
\text { Insulin }(\mathrm{pmol} / \mathrm{l})\end{array}$ & $\begin{array}{l}2.92 \\
1.52\end{array}$ & $\begin{array}{l}1.54-5.80 \\
1.13-2.19\end{array}$ & $\begin{array}{l}0.0012 \\
0.0001\end{array}$ & $\begin{array}{l}2.62 \\
1.16\end{array}$ & $\begin{array}{l}1.63-4.36 \\
0.80-1.60\end{array}$ & $\begin{array}{l}0.0001 \\
0.39\end{array}$ \\
\hline $\begin{array}{l}\text { Hip C (cm) } \\
\text { Insulin (pmol/l) }\end{array}$ & $\begin{array}{l}2.10 \\
1.81\end{array}$ & $\begin{array}{l}1.25-3.58 \\
1.34-2.62\end{array}$ & $\begin{array}{l}0.0038 \\
0.0004\end{array}$ & $\begin{array}{l}1.38 \\
1.40\end{array}$ & $\begin{array}{l}1.00-1.92 \\
1.02-1.83\end{array}$ & $\begin{array}{l}0.0036 \\
0.022\end{array}$ \\
\hline $\begin{array}{l}\operatorname{BMI}\left(\mathrm{kg} / \mathrm{m}^{2}\right) \\
\text { Insulin }(\mathrm{pmol} / \mathrm{l})\end{array}$ & $\begin{array}{l}2.16 \\
1.71\end{array}$ & $\begin{array}{l}1.23-3.77 \\
1.27-2.47\end{array}$ & $\begin{array}{l}0.006 \\
0.0012\end{array}$ & $\begin{array}{l}2.50 \\
1.19\end{array}$ & $\begin{array}{l}1.65-3.83 \\
0.82-1.61\end{array}$ & $\begin{array}{l}0.0001 \\
0.31\end{array}$ \\
\hline $\begin{array}{l}\text { Triceps (mm) } \\
\text { Insulin (pmol/l) }\end{array}$ & $\begin{array}{l}1.23 \\
1.87\end{array}$ & $\begin{array}{l}0.62-2.20 \\
1.37-2.72\end{array}$ & $\begin{array}{l}0.52 \\
0.0003\end{array}$ & $\begin{array}{l}1.25 \\
1.45\end{array}$ & $\begin{array}{l}0.82-1.90 \\
1.06-1.90\end{array}$ & $\begin{array}{l}0.30 \\
0.0096\end{array}$ \\
\hline
\end{tabular}

See Table 4 for standard deviations of the independent vari- Results for insulin were adjusted for age and obesity index (or ables.

SRR, Standardized relative risk; glucose)

those with only obesity (4.6-fold) or hyperinsulinaemia (9.3-fold).

\section{Discussion}

To our knowledge, this is the first prospective study to demonstrate NIDDM incidence in Taiwan. Incidence data on Chinese populations are scarce. Previous studies were carried out largely in high-risk groups such as Pima Indians and Mexican-Americans. For the lower risk groups, long term follow-up studies have been unfortunately carried out using different criteria. Caution should be exercised when comparing NIDDM incidence between studies because of the different diagnostic procedures and age distributions. In our study, NIDDM diagnosis was based on the WHO criterion of fasting plasma glucose. Our recent national nutrition survey data [17] showed that diabetes prevalence may increase considerably by using oral glucose tolerance test (OGTT) as compared to the fasting plasma glucose test, particularly in women. Similar results have been reported from the NHANES study [18]. The prevalence data in our second examination showed that, for subjects aged 3574 , using OGTT for those with fasting glucose over $6.1 \mathrm{mmol} / \mathrm{l}$ instead of using fasting data alone will increase NIDDM prevalence from $7.4 / 100$ to $8.6 / 100$ (16.8\% increase) in men and from $7.4 / 100$ to $9.0 / 100$ ( $23.7 \%$ increase) in women. It has been suggested that the WHO criteria of fasting glucose for diagnosis of diabetes should be lowered. We used fasting plasma glucose level $7.8 \mathrm{mmol} / \mathrm{l}$ or greater as the criteria in the present study at both baseline and follow-up. 


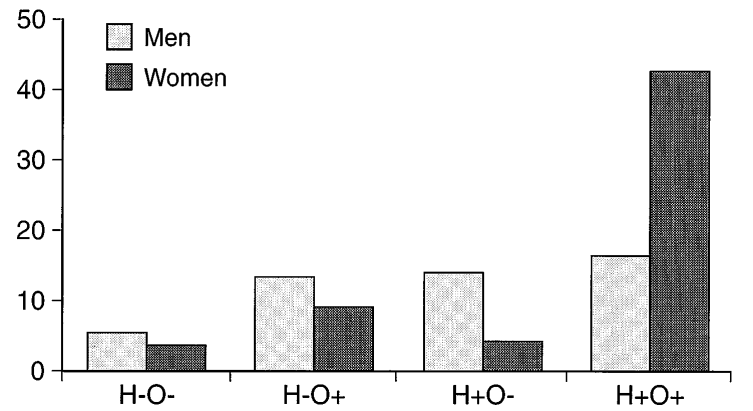

Fig. 2. NIDDM incidence (per 1000 person years) by obesity $(\mathrm{O}+$ positive, $\mathrm{O}-$ negative $)$ and hyperinsulinaemia $(\mathrm{H}+$, $\mathrm{H}-$ ). Statistical significance for men: $\mathrm{p}=0.0113$ for obesity; $\mathrm{p}=0.0585$ for hyperinsulinaemia; no significant interaction. For women: $p=0.1964$ for obesity; $p=0.5369$ for hyperinsulinaemia; $\mathrm{p}=0.0106$ for interaction

The incidence may be different from that defined by OGTT. However, this difference may not be substantial. On one hand, we have included in the population at risk some prevalent cases who were not identified by the fasting glucose criterion. On the other hand, some incident cases that should have been identified by the OGTT criteria were missed at the follow-up. These two numbers may cancel each other out. Incomplete follow-up could also affect the incidence estimates. In this study, women lost to follow-up tended to be more obese than those who were not. Therefore, the incidence estimates obtained pertain to those who were successfully followed-up.

Data from the review by Wilson et al. [19] indicated that the incidence rates were between 5 and 10 per 1000 for those aged 50 years or over in the United States. As compared to this study, our age-adjusted rates of 9.3/1000 in both men and women for 35-74 year age group were similar. The rates for age 55-64 (11.6/1000 in men and 12.7/1000 in women) in the present study also tended to be higher than those in Wilson et al.'s report for those aged 50 and over. More recent studies on NIDDM incidence have been carried out for non-Hispanic whites [10] and reported the cumulative rates of 1.1, 2.6, and $4.1 \%$ for age 35-, 45-, and 55-64 groups, respectively. However, personyear incidence data were not available in this report for direct comparisons with our results. Our NIDDM incidence also appeared to be higher than that of a Swedish study with compatible mean age [4] in which a rate of 4.6 per 1000 person-years can be calculated. A recent report from Daqing, mainland China [20] showed that the NIDDM incidence rates for those aged 25-74 (1.37/1000 in men and 1.25/1000 in women) were much lower than what we found in Taiwan. They used 2-h post-breakfast plasma glucose at baseline for exclusion but used presence of glucose in 2-h post-breakfast urine as measured by urine stick to identify incident cases at follow-up, which may artificially lower the incidence.
The present study showed that diabetes incidence increased largely from the third to the fourth quartile of baseline glucose level. The incidence increased 11fold in men and 8-fold in women compared to the second quartile once plasma glucose level reached $5.79 \mathrm{mmol} / \mathrm{l}$. For prevention of NIDDM this is an important reference for clinicians to identify groups at high risk of developing NIDDM in the community.

Obesity has been suggested as an important risk factor for diabetes in various countries and ethnic groups [3, 21-24]. In the Framingham study, BMI significantly predicted 8-year incidence of NIDDM independent of blood pressure, cardiovascular disease and lipids in both genders [21]. The present study demonstrated the essential relationship of not only BMI but also central obesity indices (such as Waist C, Subscap, and WHR) to the incidence of NIDDM among men and women. The importance of central obesity has also been consistently found by others [21-24].

Among the indices of abdominal fat accumulation, WHR was traditionally frequently used. However, our study showed that waist circumference was more sensitive as an index for predicting NIDDM incidence than WHR, with the highest standardized RR among the obesity indices of 2.92 in men and 2.62 in women (Table 5). Whereas for WHR, it was 1.75 in men and 1.66 in women. This phenomenon was in part due to a significant relation between Hip C and NIDDM risk. It is suggested that the measurement of waist circumference is a convenient and effective approach when searching for a group at high-risk of developing NIDDM.

Our analyses showed a stronger relationship between NIDDM incidence and obesity in women than in men, particularly for Subscap, BMI and Arm C. Almost all the obesity indices were still significantly associated with NIDDM incidence even after the adjustment of insulin concentration in women; whereas in men the relative risks became moderate or even non-significant in some indices. In our population, women were younger than men in both non-diabetic and diabetic groups (Table 2). Also the variations of all obesity indices in women were either similar or slightly larger than those in men. Thus the remarkable relationship between obesity and NIDDM incidence in women did not result from older age or from larger variations in obesity indices in women than in men. Another reason may be the high fat mass (in proportion to body weight) in women. In a study of healthy Europeans [25], women with a mean BMI of less than $25 \mathrm{~kg} / \mathrm{m}^{2}$ had higher fat mass and higher NIDDM incidence than men. This may also be attributed to less exercise in women than in men [26].

The notable association between insulin and NIDDM incidence in both sexes is similar to that for high diabetes risk groups such as Mexican Americans [8], 
Pima Indians [27] and Nauruans [10]. Our study also showed that in men the effect of insulin level was independent of all the obesity indices in logistic regression. This result was further strengthened by the finding shown in Figure 2. In men hyperinsulinaemia per se and obesity per se without the presence of the other can lead to significantly increased risk of NIDDM. This seems to indicate that obesity and hyperinsulinaemia do not necessarily have to occur in a fixed sequence in the pathogenesis of NIDDM. Vast amounts of literature have shown that hyperinsulinaemia often coexists with obesity [28]. The causal sequence of obesity and hyperinsulinaemia is controversial. A recent study [29] has shown that normalizing plasma insulin can reduce food intake and the rate of weight gain. Further research on this is required.

In women, however, the effect of hyperinsulinaemia on NIDDM risk is small in the absence of obesity. In the obese women, hyperinsulinaemia exerts a synergistic effect on NIDDM incidence. On the other hand, in the absence of hyperinsulinaemia, the predictive role of obesity was there. The logistic regression data indicated that effect of obesity in women was independent of insulin value. But insulin effect was not independent of obesity in women. Perhaps in women it is more likely that obesity leads to hyperinsulinaemia which in turn produces NIDDM in women. Further investigation of the developmental difference in NIDDM between men and women is warranted.

In conclusion, the present study demonstrated a United States population standardized NIDDM incidence rate of 9.3/1000 (CI 5.8-12.8) in Chinese men and 9.3/1000 (CI 6.2-12.4) in Chinese women who lived in Taiwan and had a mean BMI slightly greater than 24. It is indicated that both an overall obesity index - BMI and abdominal fat indices can predict NIDDM risk. The effects of hyperinsulinaemia and obesity on NIDDM risk were independent of each other in men. But the effect of synergistic interaction of hyperinsulinaemia and obesity was profound in women.

Acknowledgements. This project was supported by Grant DOH8202-1027, DOH83-TD-015, DOH84-TD-006 and DOH85-TD-026 from the Department of Health, Executive Yuan, ROC. S.-L.W. is a postdoctoral fellow supported by the National Science Committee. The expert assistance of J.-Y. Chen and C.-J. Yeh in data analysis are greatly appreciated.

\section{References}

1. Wu KW, Way DC (1986) Survey for diabetes prevalence among Taipei citizens aged 40-69 years in 1985. J Formosan Med Assoc 85: 1069-1077

2. Yang N-P, Lee S-Y, Chou P (1990) Community-based epidemiological study on hypertension and diabetes: community-based preventive medicine by Yang-Ming crusade in 1989. Chin Med J (Taipei) 46: 134-146
3. Department of Statistics, Ministry of the Interior (1950, 1994) National survey of general life situation in Taiwan area, Republic of China. Forever-New, Taipei, Taiwan.

4. Ohlson LO, Larsson B, Svardsudd K, et al (1985) The influence of body fat distribution on the incidence of diabetes mellitus: 13.5 years of follow-up of the participants in the study of men born in 1913. Diabetes 34: 10551058

5. Bergstrom RW, Newell-Morris LL, Leonetti DL, Shuman WP, Wahl PW, Fujimoto WY (1990) Association of elevated fasting C-peptide level and increased intra-abdominal fat distribution with development of NIDDM in JapaneseAmerican men. Diabetes 39: 104-111

6. Lundgren H, Bengtsson C, Blohme G, Lapidus L, Sjostrom L (1989) Adiposity and adipose tissue distribution in relation to incidence of diabetes in women: results from a prospective population study in Gothenburg, Sweden. Int J Obes 13: 413-423

7. Stolk RP, Van Splunder IP, Schouten JSAG, Witteman JCM, Hofman A, Grobbee DE (1993) High blood pressure and the incidence of non-insulin dependent diabetes mellitus: findings in a 11.5 year follow-up study in the Netherlands. European J Epidemiol 9: 134-139

8. Haffner SM, Hazuda HP, Mitchell BD, Patterson JK, Stern MP (1991) Increased incidence of type II diabetes mellitus in Mexican Americans. Diabetes Care 14: 102-108

9. Saad MF, Knowler WC, Pettitt DJ, Nelson RG, Mott DM, Bennett PH (1988) The natural history of impaired glucose tolerance in the Pima Indians. N Engl J Med 319: 15001506

10. Sicree RA, Zimmet PZ, King HOM, Coventry JS (1987) Plasma insulin response among Nauruans: prediction of deterioration in glucose tolerance over 6 yr. Diabetes 36: 179186

11. Yeh C-J, Pan W-H, Bai C-H et al. (1994) Curvilinear relations between age and homeostatic parameters in Chinese. Thromb Haemost 72: 239-243

12. WHO Diabetes Study Group (1980) WHO Expert Committee On Diabetes Mellitus. World Health Organisation Technical Report Series 646, Geneva

13. Teh B-H, Pan W-H, Chen C-J (1996) The reallocation of body fat toward the abdomen persists to very old age, while body mass index declines after middle age in Chinese. Int $\mathbf{J}$ Obesity 20: 683-687

14. Breslow NE, Day NE (1987) Rates and rate standardization. In: Heseltine E (eds) Statistical methods in cancer research: Volume 2. The design and analysis of cohort studies. International Agency for Research on Cancer No. 82, Oxford, pp 48-79

15. Rothman KJ (1986) Modern epidemiology. Little Brown, Boston

16. SAS Institute Inc. (1996) SAS/STAT Software: changes and enhancements through release 6.11. SAS Institute Inc., Cary, NC

17. Huang P-C, Pan W-H (1994) Annual Report of Nutrition and Health Surveillance in Taiwan (NAHSIT) Department of Health, The Executive Yuan, Taipei

18. Crowie CC, Harris MI, Eberhardt MS (1994) Frequency and determinants of screening for diabetes in the U.S. Diabetes Care 17: 1158-1163

19. Wilson PWF, Anderson KM, Kannel WB (1986) Epidemiology of diabetes mellitus in the elderly - the Framingham study. Am J Med 80: 3-9

20. Hu Y-H, Li G-W, Pan X-R, et al. (1994) Incidence of NIDDM in Daqing and forecasting of NIDDM in China in $21^{\text {st }}$ century. Chung-Hua Nei Ko Tsa Chih Chinese Journal of Internal Medicine 33(3):173-175 
21. Carey DG, Jenkins AB, Campbell LV, Freund J, Chisholm DJ (1996) Abdominal fat and insulin resistance in normal and overweight women: direct measurements reveal a strong relationship in subjects at both low and high risk of NIDDM. Diabetes 45: 633-638

22. Feskens EJM, Kromhout D (1989) Cardiovascular risk factors and the 25-year incidence of diabetes mellitus in middle-aged men: the Zutphen study. Am J Epidemiol 130: 1101-1108

23. Haffner SM, Stern MP, Mitchell BD, Hazuda HP, Patterson JK (1990) Incidence of type II diabetes in Mexican Americans predicted by fasting insulin and glucose level, obesity, and body-fat distribution. Diabetes 39: 283-288

24. Stern MP, Haffner SM (1986) Body fat distribution and hyperinsulinaemia as risk factors for diabetes and cardiovascular disease. Arteriosclerosis 6: 123-130
25. Ferrannini E, Vichi S, Beck-Nielsen H, Laakso M, Paolisso G, Smith U (1996) Insulin action and age. Diabetes 45: 947953

26. The Executive Yuan (1994) Health Statistics: Official Statistics. Taipei

27. Lillioja S, Mott DM, Howard BV, et al. (1988) Impaired glucose tolerance as a disorder of insulin action. Longitudinal and cross-sectional studies in Pima Indians. N Engl J Med 318: 1217-1225

28. Chi JM, Sun MZ (1993) Hyperinsulinaemia in obesity and diseases of internal medicine. Chung-Hua Nei Ko Tsa Chih Chinese Journal of Internal Medicine. 32(10):661-663

29. Campfield LA, Smith FJ, Mackie G, et al. (1995) Insulin normalization as an approach to the pharmacological treatment of obesity. Obesity Research 3 [Suppl 4]:591S-603S 